\title{
Plasticity AND Workability of Aluminium AlloY AT WARM
}

\author{
KAPUSTOVA, M. \& MARTINKOVIC, M.
}

Abstract: Warm forging of drop forgings represents a lucrative method of precise forgings production due to energy and time savings, obtaining of higher surface quality and dimension precision of forged pieces in comparison with hot forming. This contribution provides information about mechanical properties, plasticity and workability of aluminium alloy at warm forming temperatures. Selected temperatures were verified by numeric simulation of upsetting forming process using finite element method.

Key words: plasticity, workability, warm forming, numeric simulation, aluminium alloy
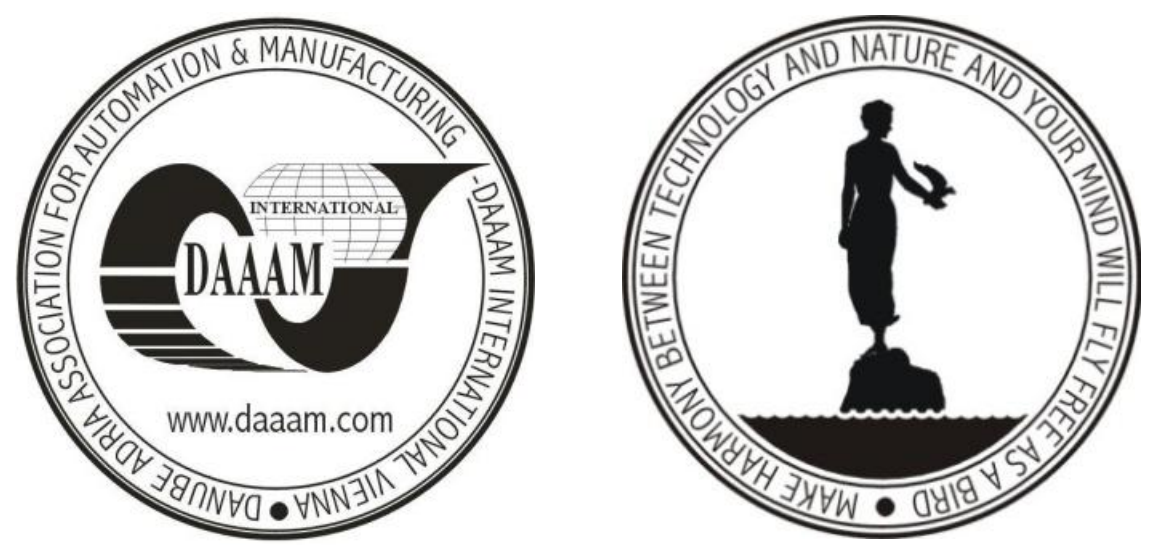

Authors' data: Assoc.Prof. Dipl.-Ing. PhD. Kapustova, M[aria]; Assoc.Prof. Dipl.Ing. PhD. Martinkovic, M[aros], Slovak University of Technology in Bratislava, Faculty of Materials Science and Technology in Trnava, Paulinska 16, 91724, Trnava, Slovakia, maria.kapustova@stuba.sk, maros.martinkovic@stuba.sk

This Publication has to be referred as: Kapustova, M[aria] \& Martinkovic, M[aros] (2012). Plasticity and Workability of Aluminium Alloy at Warm, Chapter 52 in DAAAM International Scientific Book 2012, pp. 633-640, B. Katalinic (Ed.), Published by DAAAM International, ISBN 978-3-901509-86-5, ISSN 1726-9687, Vienna, Austria

DOI: $10.2507 /$ daaam.scibook.2012.52 


\section{Introduction}

The warm forming process passes at temperatures which are over recovery temperatures but below down hot forging temperatures. This forming process can obtain higher degree deformation in comparison with cold forming. Warm forming passes with partial strain hardening of metal above recovery temperature and below temperature of recrystallization (Forejt \& Piska, 2006). Energy and time savings at warming up (Forcellese \& Gabrielli, 2000) and higher surface quality and dimension precision of forged pieces after forming in comparison with hot forming are important arguments for investigation of properties of aluminium alloy at warm forming temperatures (Novotny, 2000). This information is necessary for further development of warm forming (Altan, T. et al., 2005).

\section{Experimental material}

The subject of plasticity and workability research at warm forming temperatures is aluminium alloy AlSiMg type, its chemical composition is in Table 1. This alloy, which belongs to the group " 6000 " of aluminium alloys, is determined primarily for hot forging. The alloy was in natural state, without any heat treatment (for instant solution treatment).

\begin{tabular}{|c|c|c|c|c|c|c|c|}
\hline Elements & Si & Mg & Fe & Cu & Mn & Cr & Al \\
\cline { 2 - 7 } & \multicolumn{7}{|c|}{ wt.\% } \\
\hline $\min$ & 0,45 & 0,4 & & & & & \\
$\max$ & 0,8 & 0,8 & 0,3 & 0,1 & 0,1 & 0,1 & rest \\
\hline
\end{tabular}

Tab. 1. Chemical composition of aluminium alloy

Suitability of examined aluminium alloy for warm bulk forming was weight by tensile test at higher temperatures (according to standard STN EN 10002-5). Cylindrical bar tensile test specimens were used. The gage length was $80 \mathrm{~mm}$, diameter $8 \mathrm{~mm}$. The specimens were tested at temperatures $20,100,150$ and $200^{\circ} \mathrm{C}$.

Strength limit $\mathrm{Rm}$, characteristics of plasticity for workability at higher temperature (reduction of area $\mathrm{Z}$, index of plasticity to rupture according to Kolmogorov $\lambda_{R}$ ), ductility A, Paur`s index of plasticity $D_{s m}$ and exponent of strain hardness $\mathrm{n}$ were calculated from measured results on three tested specimen at each tested temperatures. The exponent of strain hardness $n$ was determined as true plastic strain at tensile strength point where plastic deformation stability is lost.

Temperature course of tensile strength $\mathrm{Rm}$ is in Fig. 1, temperature courses of percentage reduction of area $\mathrm{Z}$ and ductility $\mathrm{A}$ are in Fig.2, temperature courses of index of plasticity according to Kolmogorov $\lambda_{R}$ and Paur`s index of forming capacity $\mathrm{D}_{\mathrm{sm}}$ are in Fig.3. Determined values of strain hardening index at examined temperatures are in Table 2. 


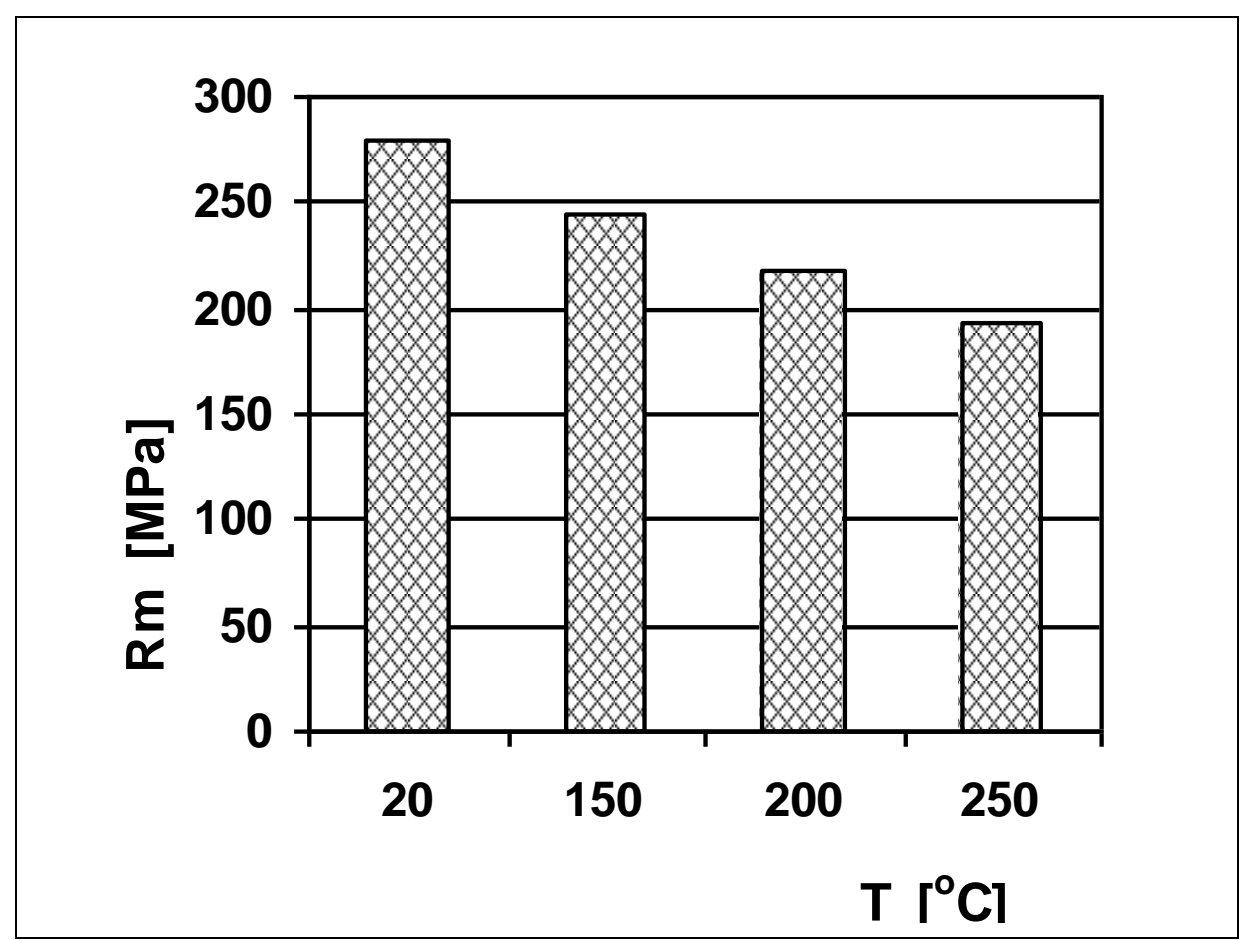

Fig. 1. Temperature course of tensile strength $\mathrm{Rm}$

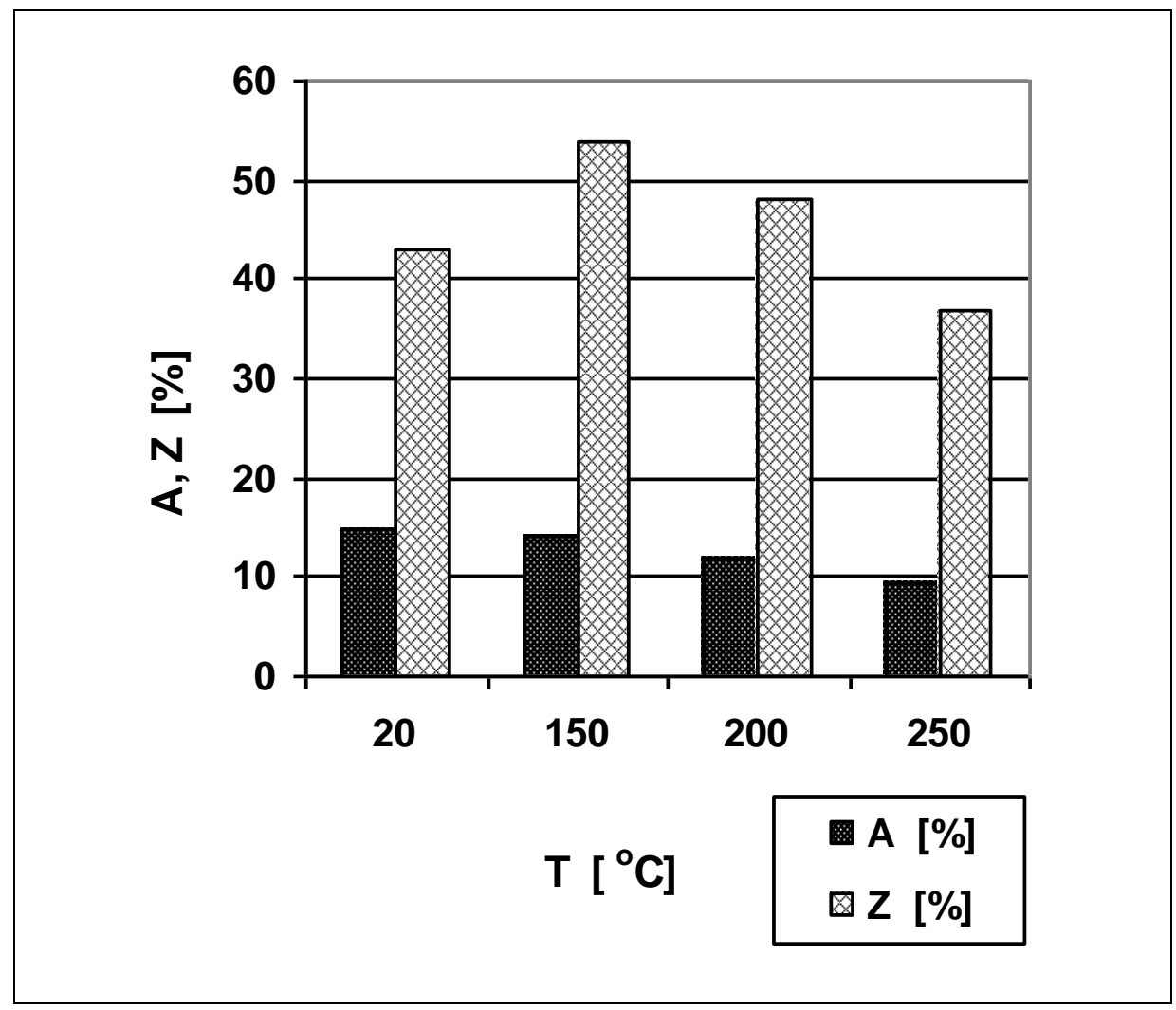

Fig. 2. Temperature courses of percentage reduction of area $\mathrm{Z}$ and ductility $\mathrm{A}$

\begin{tabular}{|c|c|c|c|c|}
\hline $\begin{array}{c}\mathrm{T} \\
{\left[{ }^{\circ} \mathrm{C}\right]}\end{array}$ & 20 & 150 & 200 & 250 \\
\hline $\mathrm{n}$ & 0,079 & 0,061 & 0,037 & 0,011 \\
\hline
\end{tabular}

Tab. 1. Values of strain hardening index $n$ 


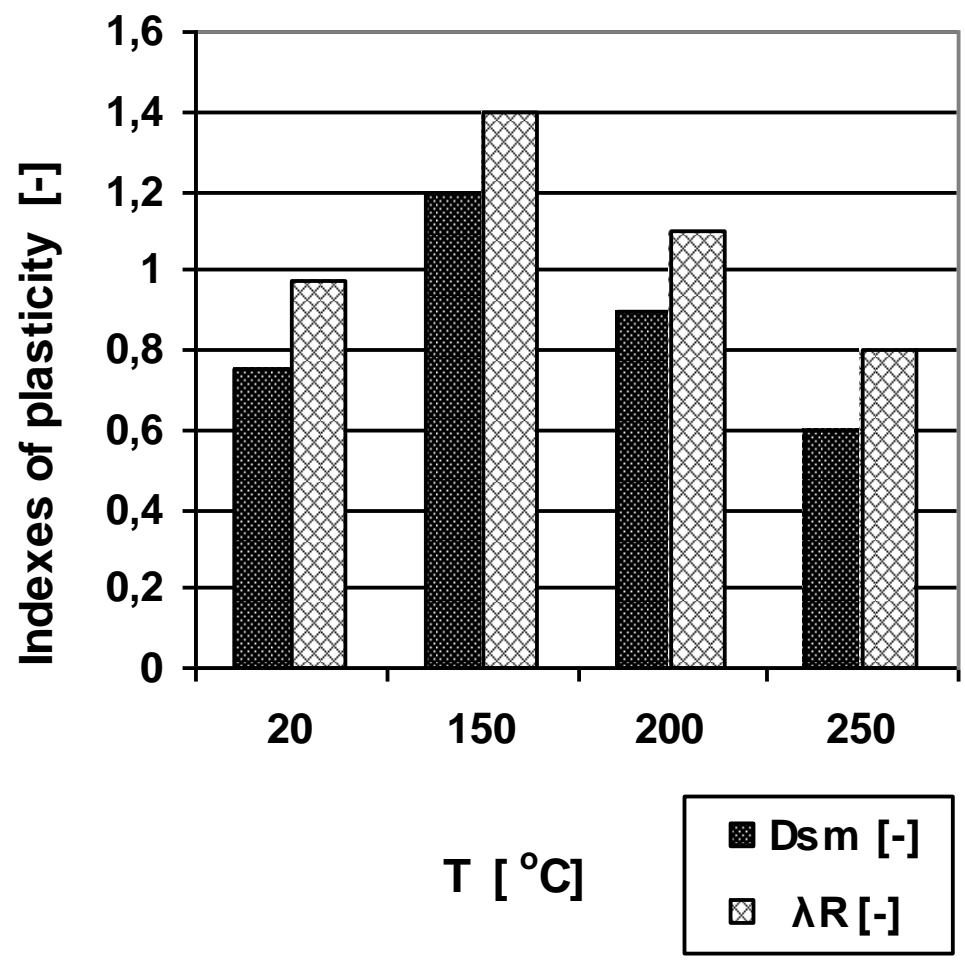

Fig. 3. Temperature courses of index of plasticity $\lambda_{R}$ and forming capacity $D_{s m}$

\section{Numeric Simulation}

The results were verified by numeric simulation of upsetting forming process using finite element method. One of the advantages of simulation programs is that they help to prove the design accuracy of the technological parameters before creation of the forming tools and start of production. Change of tool geometry or technological parameters can also eliminate possible failures in the preparation production phase (Lee \& Jou, 2003). A simulation software MSC Super Forge was used. The parameters of numeric simulation was: forging on hydraulic press, tool temperature $100^{\circ} \mathrm{C}$, friction coefficient 0,4 , cylindrical bar from aluminium alloy 6060 with diameter $25 \mathrm{~mm}$ and high $50 \mathrm{~mm}$, temperatures 150,200 and $250^{\circ} \mathrm{C}$, high after deformation $30 \mathrm{~mm}$. The results of numeric simulation of the process - effective plastic strain, temperature in longitudinal section in the middle of cylindrical bar and contact pressure were observed. Results of upsetting process simulation are in fig. 4 (corresponding values marked by dots). During deformation at $250^{\circ} \mathrm{C}$ in the middle of the work piece the temperature of the material increased to $270^{\circ} \mathrm{C}$, which is over the recrystallization temperature and recrystallization can bee passed. This result was experimentally verified. Warm forming of the real part from aluminium alloy at $250^{\circ} \mathrm{C}$ was realized at the same basic parameters as are described hereinbefore. Microstructure changes of the deformed sample were analysed. 


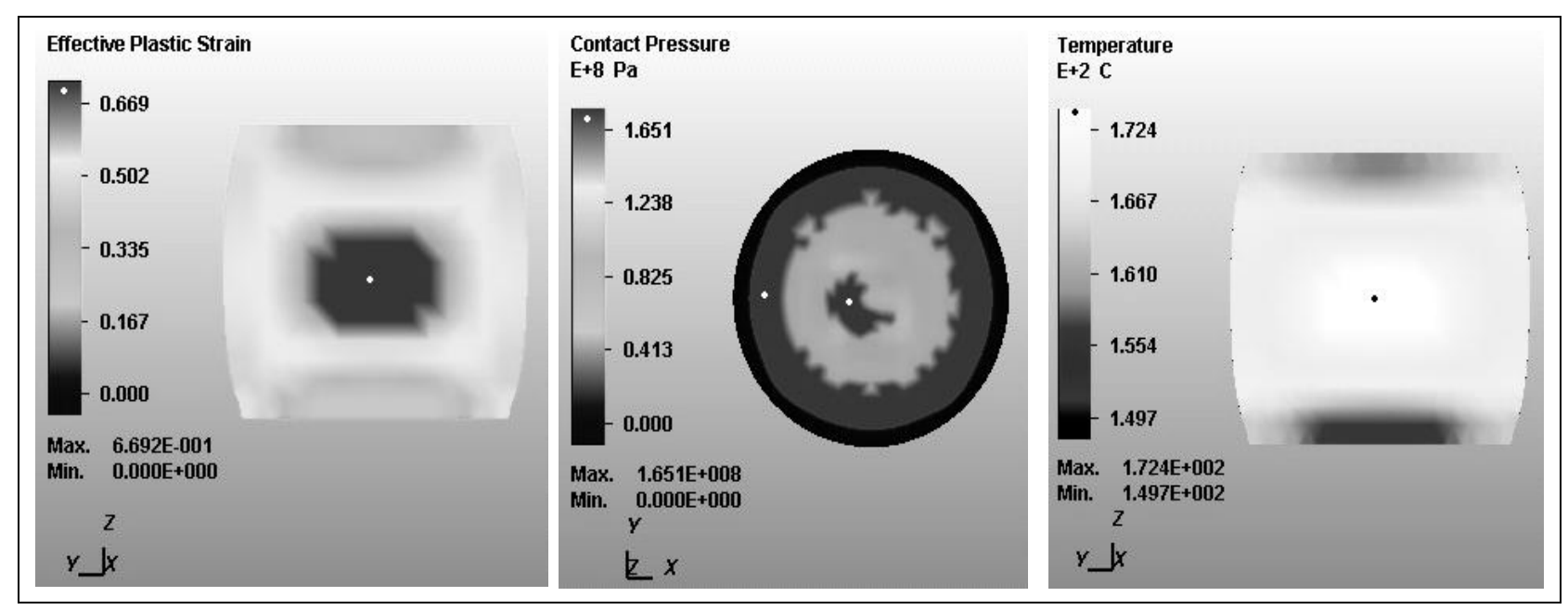

$\mathrm{a}$

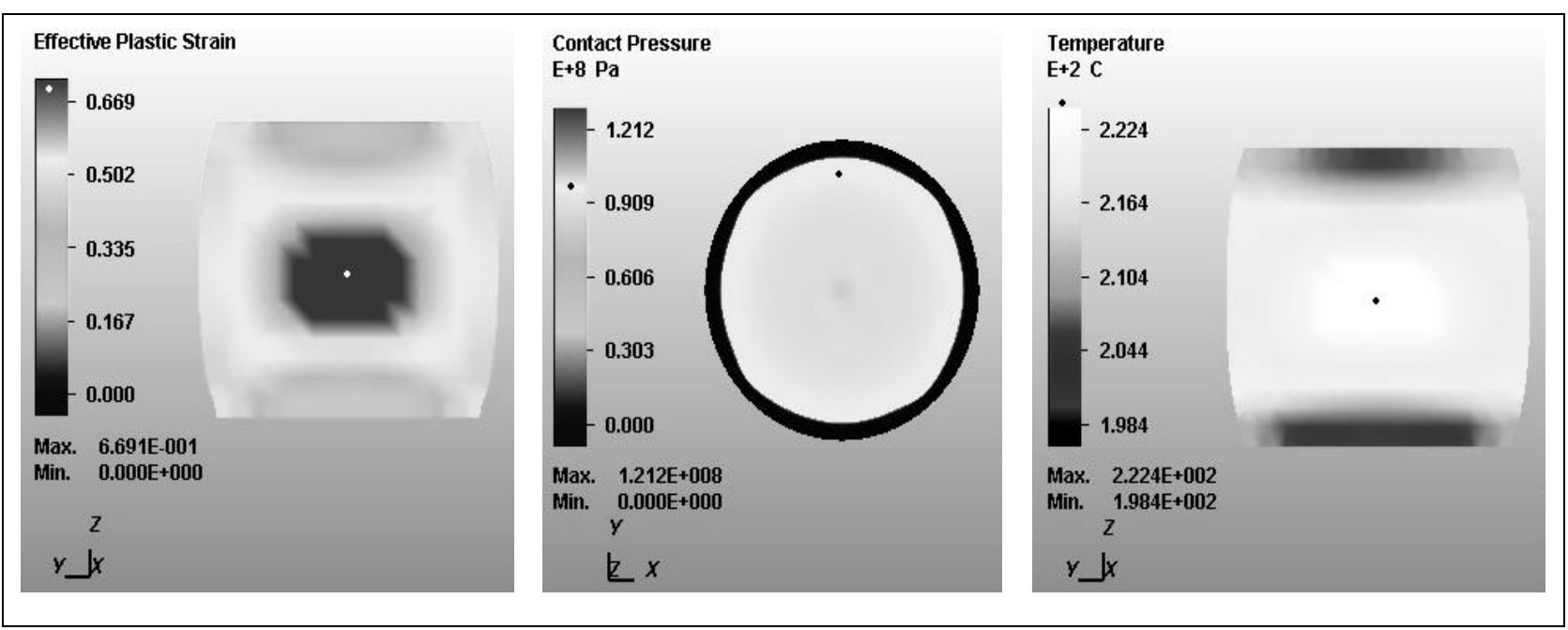

b
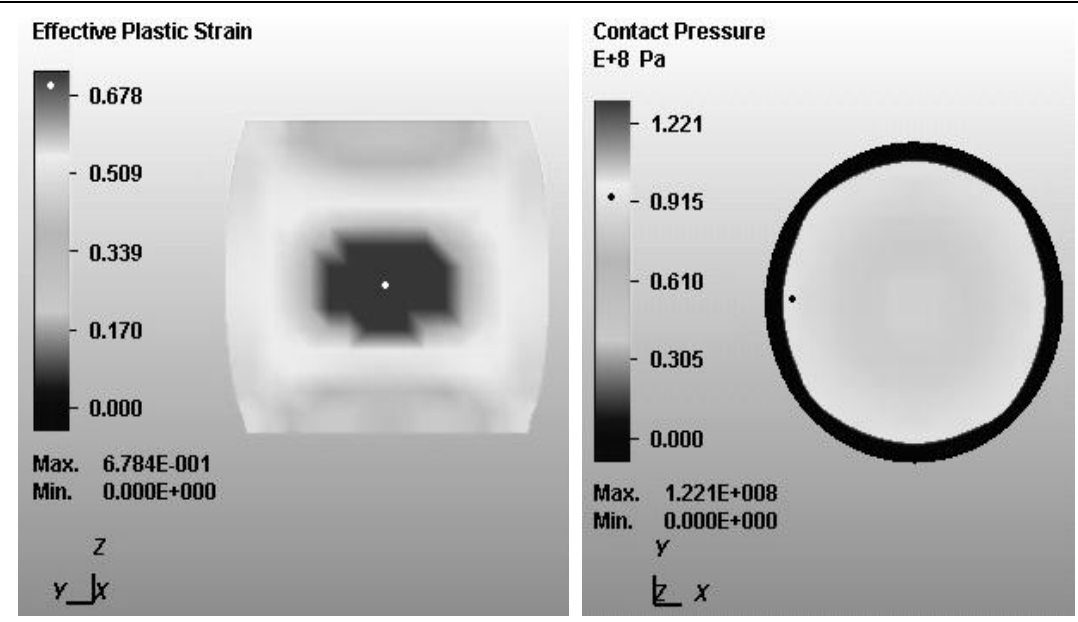

Temperature

$\mathrm{E}+2 \mathrm{C}$

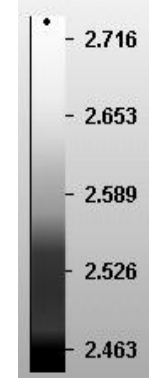

Max. $2.716 \mathrm{E}+002$

Min. $2.463 \mathrm{E}+002$

$z$

$y \_x$

C

Fig. 4. Results (effective plastic strain, contact pressure and temperature) of upsetting process simulation at $150^{\circ} \mathrm{C}(\mathrm{a}), 200^{\circ} \mathrm{C}$ (b) and $250^{\circ} \mathrm{C}$ (c) 


\section{Microstructure analysis}

The structure of aluminium alloy material was observed with about 50x magnification of light microscope on metallographic cut of longitudinal section in the middle of cylindrical bar. The metallographic cut was mechanical grinded and polished, chemical etched in Keller etcher (1,5 ml HF, $3 \mathrm{ml} \mathrm{HNO}_{3}, 100 \mathrm{ml} \mathrm{H} \mathrm{H}_{2} \mathrm{O}$ ). An example of aluminium alloy structure in basic state is in Fig. 5, an example of aluminium alloy structure after deformation is in Fig. 6.

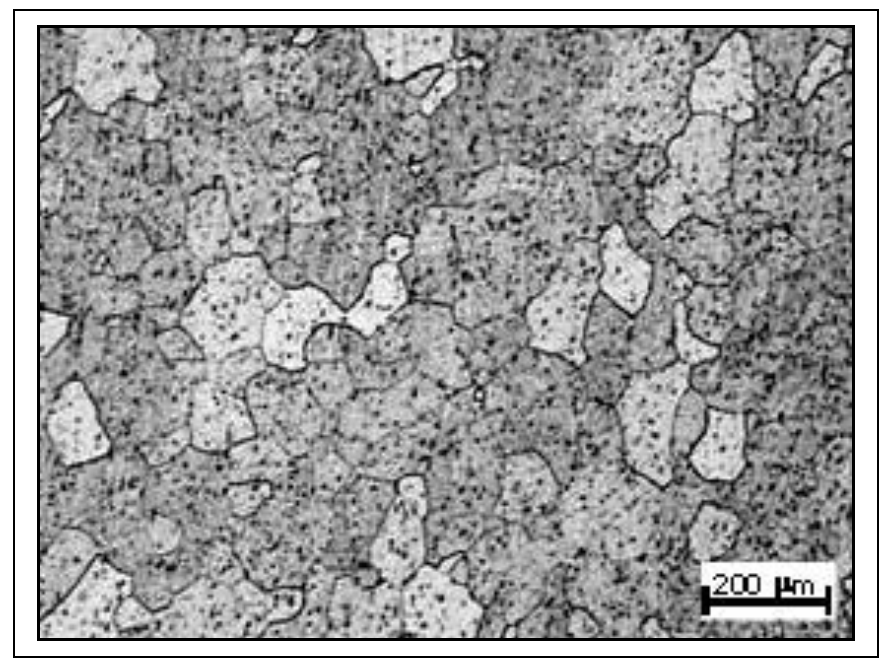

Fig. 5. An example of the aluminium alloy structure in basic state

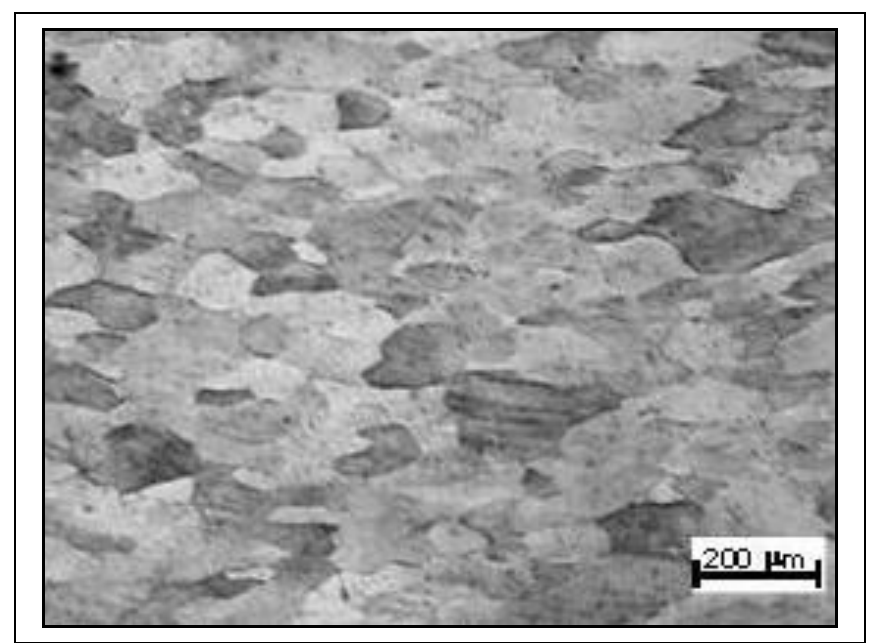

Fig. 6. An example of the aluminium alloy structure after deformation

The strain of probes on their sections was obtained by stereological measured by measurement of degree grain boundaries deformation - degree of grain boundaries orientation (Saltykov, 1970). The method of oriented test lines was used. Test lines were placed perpendicular and parallel to the grain boundaries orientation direction effected by straining (Russ \& Dehoff, 2000). From the relative number (number to unit of length) of parallel test lines intersections with grain boundaries $\left(\mathrm{P}_{\mathrm{L}}\right)_{\mathrm{P}}$ and perpendicular lines ones $\left(\mathrm{P}_{\mathrm{L}}\right)_{\mathrm{O}}$ was total relative surface area (area to unit test volume) $\left(\mathrm{S}_{\mathrm{V}}\right)_{\text {Tот }}$ of grains estimated according equation (1) and planar oriented part 
of relative surface area $\left(\mathrm{S}_{\mathrm{V}}\right)_{\mathrm{OR}}$ of grains estimated according equation (2). The relative measure precision was always smaller then $10 \%$ with reliability $90 \%$. Degree of grain boundaries orientation was estimated as $\left(\mathrm{S}_{\mathrm{V}}\right)_{\mathrm{OR}}$ to $\left(\mathrm{S}_{\mathrm{V}}\right)_{\mathrm{TOT}}$ ratio.

$$
\begin{aligned}
& \left(\mathrm{S}_{\mathrm{V}}\right)_{\text {TOT }}=\left(\mathrm{P}_{\mathrm{L}}\right)_{\mathrm{O}}+\left(\mathrm{P}_{\mathrm{L}}\right)_{\mathrm{P}} \\
& \left(\mathrm{S}_{\mathrm{V}}\right)_{\mathrm{OR}}=\left(\mathrm{P}_{\mathrm{L}}\right)_{\mathrm{O}}-\left(\mathrm{P}_{\mathrm{L}}\right)_{\mathrm{P}}
\end{aligned}
$$

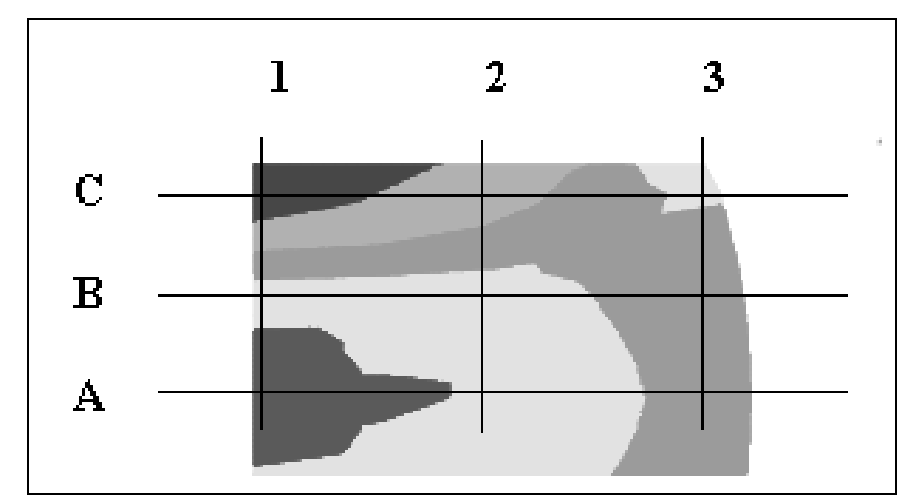

Fig. 7. Positions of deformation analysis

The results of grain boundaries orientation measurement in different places (see Fig. 5.) of deformed bulk of aluminium alloy specimen are in Tab. 3.

\begin{tabular}{|c|c|c|c|}
\hline \multirow{2}{*}{ Position } & \multicolumn{3}{|c|}{ Orientation [\%] } \\
\cline { 2 - 4 } & 1 & 2 & 3 \\
\hline C & 19 & 27 & 40 \\
\hline B & 18 & 28 & 33 \\
\hline A & 0 & 20 & 32 \\
\hline
\end{tabular}

Tab. 3. Measured grain boundaries orientation in different places of aluminium alloy specimen

\section{Discussion}

From the result of mechanical testing at warm temperatures results, that the best plastic properties of alloy are at $150^{\circ} \mathrm{C}$, on the other hand tensile strength has the maximum value. From the values of strain hardening index we can see, that area of equilibrium plastic deformation over $200^{\circ} \mathrm{C}$ rapidly decreased. Numeric simulation of upsetting process at warm temperatures 150,200 and $250^{\circ} \mathrm{C}$ showed very good material flow. At $250^{\circ} \mathrm{C}$ during deformation the temperature of the material in the middle of the work piece increased to $270^{\circ} \mathrm{C}$ (see Fig. 4c), which is over the recrystallization temperature which was verified by microstructural analysis.

Microstructural analysis showed coincidence of numeric simulation with real state. In all places on metallographic cut degree of orientation was in very good coincidence with numeric simulated effective strains with exception of area in the 
middle of the specimen. The values of grain boundaries orientation were from 20 to $40 \%$, but in the middle of the specimen was equal zero - in this place recrystallization was passed. It means that the temperature reached assumed value.

The result showed possibilities of forming of aluminium alloy of group " 6000 " in natural state at warm temperature. From these result an optimal warm forming temperature for the alloy $\mathrm{AlSiMg}$ appears $200^{\circ} \mathrm{C}$. In comparison with $150^{\circ} \mathrm{C}$ is at this temperature lower plasticity, on the other hand lower strength and lower contact pressure (see Fig. 4). It led to greater lifetime of tool and lower machine energy.

\section{Conclusion}

On the basis of mentioned results it is possible to apply the technology of warm forming. The results of numeric simulation confirm that the choice of the temperature at warm forging was good. Forming of aluminium alloy in natural state at warm temperature lead to time and energy consumption saving in comparison with hot forming. Also warm forming lead to better surface quality and higher dimension precision of forming pieces. The results can be used in precision die forging in closed die, which experimental and numerical verification must follow.

\section{Acknowledgements}

This research is supported by VEGA Grant No. 1/1041/11 and VEGA Grant No. 1/2594/12 which are supported by Slovak Republic Ministry of Education.

\section{References}

Altan, T. et al. (2005). Cold and Hot Forging: Fundamentals and Applications. ASM International, ISBN 0-87170-805-1, Ohio

Forcellese, A., \& Gabrielli, F. (2000). Warm forging of aluminium alloys: a new approach for time compression of the forging sequence. International Journal of Machine Tools and Manufacture, Vol. 40, pp. 1285-1297, ISSN 0890-6955

Forejt, M. \& Piska, M. (2006). Theory of machining, forming and tools, CERM, ISBN 80-214-2374-9, Brno

Lee, R. S., \& Jou, J. L. (2003). Application of numerical simulation for wear analysis of warm forging die. Journal of material processing technology, Vol.140, pp. 43-48

Novotny, K. (2000). FORM 2000, Possibilities of warm forming application, pp. 211213, ISBN 80-214-1661-0, Brno, September 19. - 20. 2000, TU Brno, Brno

Russ, J., C. \& Dehoff, R., T. (2000). Practical stereology, Plenum Press, 0-30646476-4, New York

Saltykov, S. A. (1970). Stereometričeskaja metallografia, Stereometric metallography, Metallurgia, 3-11-1 88-70, Moscow 